\title{
PENGETAHUAN DAN PERSEPSI WANITA USIA SUBUR TERHADAP RUANG LAKTASI DI INSTANSI PEMERINTAH WILAYAH KOTA DENPASAR TAHUN 2017
}

\author{
Nyoman Triana Aryati*, Ketut Hari Mulyawan, I Ketut Tangking Widarsa \\ Program Studi Kesehatan Masyarakat Fakultas Kedokteran Universitas Udayana \\ *Email: triana.aryati@gmail.com
}

\begin{abstract}
ABSTRAK
Tantangan dalam pemberian ASI salah satunya dihadapi oleh para ibu bekerja yang merasa kesulitan untuk memberikan ASI maupun memerah ASI pada waktu kerja, baik dikarenakan tidak adanya fasilitas, cuti melahirkan yang tidak fleksibel sampai tidak diberikannya kesempatan menyusui. Pada tahun 2013 telah diterbitkan Peraturan Menteri Kesehatan (Permenkes) nomor 15 tahun 2013 tentang tata acara penyediaan fasilitas khusus menyusui atau memerah air susu ibu seperti ruang laktasi. Tujuan dari penelitian ini adalah untuk mengetahui tingkat pengetahuan dan persepsi Wanita Usia Subur (WUS) yang bekerja terhadap ruang laktasi di instansi pemerintah wilayah Kota Denpasar tahun 2017. Penelitian ini merupakan penelitian deskriptif kuantitatif dengan rancangan cross-sectional. Sampel penelitian adalah 79 WUS yang bekerja. Pemilihan tempat kerja yaitu instansi pemerintah yang memiliki ruang laktasi di Wilayah Kota Denpasar dan pemilihan sampel secara stratified proportional random sampling. Pengumpulan data pengetahuan dan persepsi dilakukan dengan menggunakan kuesioner dan data dianalisis secara deskriptif. Hasil penelitian didapatkan 72,2\% WUS memiliki pengetahuan baik, 27,8\% memiliki pengetahuan cukup, dan tidak ada yang memiliki pengetahuan kurang. Untuk persepsi terhadap ruang laktasi didapatkan 64,6\% WUS memiliki persepsi baik dan 35,4\% memiliki persepsi kurang baik. Dapat disimpulkan bahwa sebagian besar WUS memiliki tingkat pengetahuan baik serta lebih dari setengah memiliki persepsi yang baik terhadap ruang laktasi. Disarankan agar menyediakan ruang laktasi sesuai dengan ketentuan serta mendukung ruang laktasi tersebut dengan meningkatkan peran tenaga kesehatan dan atasan tempat bekerja agar lebih mensosialisasikan pemanfaatan ruang laktasi.

Kata Kunci: awareness, perception, lactation room, reproductive age women
\end{abstract}

\begin{abstract}
Working mothers faces challenges to provide exclusive breastfeedings due to limited facility to breastfed or to express breast milk within working hours, inflexible maternity leave and no breastfeeding time within working hours. In 2013, the Ministry of Health (MoH) adopted MoH regulation (Permenkes) No 15/2013 about standard procedure to provide breastfeeding or expressing breast milk facility, such those called as "ruang laktasi"/lactation room. This study aims to explore awareness and perception of reproductive age working women (WUS) on lactation room at governments institution in City of Denpasar in 2017. This was a descriptive quantitative study with cross-sectional design. Study sample were 79 WUS. Working places included on the study were those that have lactation room and samples were selected by stratified random sampling. Data on awareness and perception were collected using questionnaire and analysed with descriptive analysis. From the study, $72.2 \%$ WUS have good awareness, $27.8 \%$ have moderate awareness and none with low awareness. For the perception on lactation room, $64.6 \%$ WUS have good perception and $35.4 \%$ have lower perception on lactation room. It can be concluded that the majority of working women have good awareness, and more than half have good perception on lactation room. It is recommended to provide lactation room and to support improvement of lactation room by improving role of health workers and supervisors at work places to extend socialization of the lactation room.
\end{abstract}

Keywords: pengetahuan, persepsi, ruang laktasi, WUS

\section{PENDAHULUAN}

Cakupan Air Susu Ibu (ASI) eksklusif di Indonesia pada tahun 2015 sebesar 55,7\%, cakupan ini masih dibawah target yang telah di tetapkan yaitu sebesar $80 \%$. Data dari Dinas Kesehatan Provinsi Bali menunjukkan cakupan ASI eksklusif di
Provinsi Bali mengalami penurunan dari tahun 2015 yaitu sebesar 72,8\% menjadi $70,7 \%$ di tahun 2016. Data dari Dinas Kesehatan Kota Denpasar menunjukkan bahwa cakupan ASI eksklusif meningkat di tahun 2015 menjadi sebesar 75,3\% dari 73\% pada tahun 2014 (Depkes RI,2015). Beberapa 
tantangan dalam pemberian ASI salah satunya dihadapi oleh para ibu bekerja yang merasa kesulitan untuk memberikan ASI maupun memerah ASI pada waktu kerja, baik dikarenakan tidak adanya fasilitas, cuti melahirkan yang tidak fleksibel sampai tidak diberikannya kesempatan menyusui (Depkes RI,2015).

Undang-undang Nomor 36 tahun 2009 tentang Kesehatan dan Peraturan Pemerintah nomor 33 tahun 2012 tentang ASI eksklusif menyebutkan bahwa pemerintah, keluarga dan masyarakat harus mendukung pemberian ASI eksklusif. Penyelenggara tempat sarana umum serta pengurus tempat kerja harus menyediakan fasilitas yang mendukung program ASI eksklusif yaitu Ruang Laktasi. Pada tahun 2013 telah diterbitkan Peraturan Menteri Kesehatan (Permenkes) nomor 15 tahun 2013 tentang tata acara penyediaan fasilitas khusus menyusui atau memerah air susu ibu seperti ruang laktasi. Penggunaan ruang laktasi di Indonesia masih terbilang minim, hal ini disebabkan oleh kurangnya pengetahuan dan fasilitas ruang laktasi yang belum memadai. Menurut Pratiwi (2016), terdapat dua faktor yang berhubungan dengan ruang laktasi, diantaranya adalah pengetahuan tentang manajemen laktasi dan dukungan lingkungan kerja (dukungan dari atasan, rekan kerja dan sesama ibu menyusui). Dengan adanya dua faktor tersebut, diharapkan partisipasi ibu dalam menggunakan ruang laktasi meningkat.

Pada penelitian yang dilakukan oleh Anun Indiana (2013), mengenai hubungan antara pengetahuan ibu bekerja tentang manajemen laktasi dan dukungan tempat kerja menyatakan bahwa terdapat hubungan yang signifikan antara pengetahuan ibu dengan pemberian ASI eksklusif pada ibu bekerja di wilayah kerja Puskesmas Kartasura. Pengetahuan yang baik akan menimbulkan keinginan ibu untuk memberikan ASI eksklusif kepada bayinya dengan memanfaatkanya pojok laktasi yang terdapat ditempat ibu bekerja. Hasil wawancara penulis yang telah dilakukan kepada 5 ibu menyusui yang bekerja di Dinas Kesehatan Provinsi didapatkan bahwa 1 ibu (20\%) menyatakan memberikan ASI kepada bayinya sehingga ibu tersebut menggunakan ruang laktasi untuk memerah, sedangkan 4 ibu (80\%) menyatakan tidak menggunakan ruang laktasi karena sudah memberikan bayinya susu formula. Alasan ibu-ibu tersebut tidak menggunakan ruang laktasi selain karena waktu bekerja yang padat juga karena memberikan susu formula dirasakan lebih praktis dan mudah. Ruang laktasi yang terdapat di Dinas Kesehatan Provinsi pun baru terbentuk kurang lebih satu tahun.

Berdasarkan uraian latar belakang diatas, maka penulis melakukan penelitian dengan judul pengetahuan dan persepsi WUS terhadap ruang laktasi di instansi pemerintah wilayah Kota Denpasar tahun 2017.

\section{METODE}

Penelitian ini adalah penelitian deskriptif kuantitatif dengan rancangan cross-sectional. Penelitian ini dilaksanakan pada empat instansi tersebut yaitu di Dinas Kesehatan Provinsi Bali, Dinas Kesehatan Kota Denpasar, dan Badan Koordinasi dan Keluarga Berencana Nasional Provinsi Bali, dan Kantor Imigrasi Kelas I Denpasar 
Pemilihan Instansi Pemerintah yang memiliki ruang laktasi di Wilayah Kota Denpasar. Kemudian pemilihan sampel WUS umur 20-35 tahun dilakukan secara stratified proportional random sampling. Data pengetahuan dan persepsi dikumpulkan dengan menggunakan kuesioner. Data yang terkumpul dianalisis secara univariat.
HASIL

\section{Karakteristik WUS}

Karakteristik WUS dalam penelitian ini meliputi umur, status perkawinan, jumlah anak, umur anak terakhir, dan memberikan ASI secara eksklusif atau tidak memberikan ASI secara eksklusif yang dapat dilihat pada tabel berikut ini

Tabel 1. Karakteristik WUS

\begin{tabular}{|c|c|c|}
\hline Karakteristik & $\mathbf{F}$ & $(\%)$ \\
\hline \multicolumn{3}{|l|}{ Umur } \\
\hline 20-27 tahun & 34 & 43,0 \\
\hline 28-35 tahun & 45 & 57,0 \\
\hline \multicolumn{3}{|l|}{ Pendidikan terakhir } \\
\hline SMP & 1 & 1.3 \\
\hline SMA & 5 & 6,3 \\
\hline DIPLOMA/PT & 73 & 92,4 \\
\hline \multicolumn{3}{|l|}{ Status perkawinan } \\
\hline Kawin & 56 & 70,9 \\
\hline Belum kawin & 23 & 29,1 \\
\hline \multicolumn{3}{|l|}{ Jumlah anak } \\
\hline Nullipara & 28 & 35,4 \\
\hline Primipara & 23 & 29,1 \\
\hline Multipara & 28 & 35,4 \\
\hline \multicolumn{3}{|l|}{ Umur anak terakhir* } \\
\hline$<6$ bulan & 7 & 13,7 \\
\hline $6-12$ bulan & 8 & 15,7 \\
\hline$>12$ bulan & 36 & 70,6 \\
\hline \multicolumn{3}{|l|}{ ASI eksklusif* } \\
\hline Iya & 38 & 74,5 \\
\hline Tidak & 13 & 25,5 \\
\hline \multicolumn{3}{|l|}{ Instansi } \\
\hline Dinkes provinsi & 34 & 43,0 \\
\hline Dinkes kota & 18 & 22,8 \\
\hline BKKBN & 11 & 13,9 \\
\hline Imigrasi & 16 & 20,3 \\
\hline
\end{tabular}

${ }^{*} \mathrm{n}=51$ (yang memiliki anak)

Berdasarkan Tabel 1 di atas dapat dilihat bahwa dari 79 WUS yang menjadi responden paling banyak berumur 28-35 tahun $(57 \%)$, hampir seluruhnya memiliki pendidikan terakhir diploma atau perguruan tinggi $(92,4 \%)$, sebagian besar WUS sudah kawin $(70, \%)$, sebanyak 35,4\% WUS belum memiliki anak demikian pula sebanyak 35,4\% WUS sudah memiliki anak lebih dari 2 orang, sebagian besar WUS yang sudah kawin memiliki anak berumur lebih dari 2 tahun $(70,6 \%)$ dimana sebagian besar WUS memberikan ASI secara eksklusif kepada bayinya $(74,5 \%)$. 
Pengetahuan WUS terhadap ruang laktasi Tingkat pengetahuan remaja putri dikategorikan menjadi tiga yaitu pengetahuan baik, cukup dan kurang.

Tabel 2. Tingkat Pengetahuan WUS

\begin{tabular}{lcc}
\hline \multicolumn{1}{c}{ Pengetahuan } & Frekuensi & (\%) \\
\hline Baik & 57 & 72,2 \\
Cukup & 22 & 27,8 \\
Kurang & 0 & 0,0 \\
\hline \multicolumn{1}{c}{ Total } & $\mathbf{7 9}$ & $\mathbf{1 0 0}$ \\
\hline
\end{tabular}

Berdasarkan Tabel 2 di atas dapat dilihat bahwa sebagian besar WUS memiliki pengetahuan yang baik tentang ruang laktasi. Dari 79 WUS sebagian besar 72,2\% memiliki tingkat pengetahuan baik dan sisanya $27,8 \%$ WUS yang memiliki tingkat pengetahuan cukup. Dilihat dari komponen pengetahuan sebagian besar WUS sudah mempunyai pengetahuan yang baik tentang definisi ruang laktasi, manfaat dan kegunaan ruang laktasi, seperti yang disajikan pada Tabel 3 di bawah ini:

Tabel 3. Pengetahuan WUS Terhadap Ruang Laktasi

\begin{tabular}{|c|c|c|c|}
\hline $\begin{array}{l}\text { No. } \\
\text { Soal }\end{array}$ & $\begin{array}{c}\text { Pengetahuan WUS Terhadap } \\
\text { Ruang laktasi }\end{array}$ & \multicolumn{2}{|c|}{$\begin{array}{l}\text { Jawaban } \\
\text { Benar }\end{array}$} \\
\hline 1 & Tempat bekerja tersedia ruang & & \\
\hline & laktasi & 61 & 77,2 \\
\hline 2 & Ruang laktasi setidaknya ada & & \\
\hline & peralatan pendukung lainnya & 32 & 40,5 \\
\hline 3 & Ruang laktasi harus di & & \\
\hline & manfaatkan & 78 & 98,7 \\
\hline 4 & Bisa digunakan untuk tempat & & \\
\hline & konseling menyusui & 72 & 91,1 \\
\hline 5 & Bisa digunakan untuk & & \\
\hline & menyimpan ASI perah & 49 & 62,0 \\
\hline 6 & $\begin{array}{l}\text { Bisa ASI eksklusif dengan } \\
\text { memanfaatkan ruang laktasi }\end{array}$ & 74 & 93,7 \\
\hline 7 & ASI tidak bisa disimpan pada & & \\
\hline & lemari es lebih dari 3 hari & 65 & 82,3 \\
\hline 8 & $\begin{array}{l}\text { Ruang laktasi perlu ada di } \\
\text { tempat bekerja }\end{array}$ & 65 & 82,3 \\
\hline 9 & Adanya ruang laktasi dukungan & & \\
\hline & dari tempat bekerja & 78 & 98,7 \\
\hline 10 & $\begin{array}{l}\text { Memiliki kesempatan untuk } \\
\text { memerah atau menyusui }\end{array}$ & 78 & 98,7 \\
\hline
\end{tabular}

11 Ruang laktasi tidak

dipergunakan untuk kebutuhan

lain

$63 \quad 79,7$

12 Fasilitas sarana dan prasarana

ruang laktasi

$63 \quad 79,7$

13 Wajib disediakan di setiap kantor dan tempat umum

Media KIE tentang ASI

7696,2

14

15 Upaya peningkatan peran

7696,2

keluarga, masyarakat dan pemerintah

$79 \quad 97,5$

Tingkat pengetahuan WUS berdasarkan karakteristik dapat di lihat pada Tabel 4 berikut ini:

Persepsi WUS terhadap ruang laktasi dapat dilihat pada Tabel 4 berikut ini:

Tabel 4. Persepsi WUS Terhadap Ruang Laktasi

\begin{tabular}{lcc}
\hline \multicolumn{1}{c}{ Persepsi } & Frekuensi & $\mathbf{( \% )}$ \\
\hline Baik & 51 & 64,6 \\
Kurang baik & 28 & 35,4 \\
\hline \multicolumn{1}{c}{ Total } & $\mathbf{7 9}$ & $\mathbf{1 0 0}$ \\
\hline
\end{tabular}

Berdasarkan Tabel 4. di atas dapat dilihat bahwa sebagian besar WUS memiliki persepsi yang baik terhadap ruang laktasi. Dari 79 WUS sebagian besar $64,6 \%$ memiliki persepsi baik. Dilihat dari komponen persepsi sebagian besar WUS sudah mempunyai persepsi yang baik, namun masih ada 35,4\% WUS yang memiliki persepsi yang kurang baik terhadap ruang laktasi seperti yang disajikan dalam Tabel 5 berikut ini

Tabel 5. Persepsi WUS Terhadap Ruang Laktasi

\begin{tabular}{|c|c|c|c|}
\hline $\begin{array}{l}\text { No. } \\
\text { Soal }\end{array}$ & $\begin{array}{c}\text { Persepsi WUS } \\
\text { Terhadap Ruang } \\
\text { Laktasi }\end{array}$ & $\begin{array}{l}\text { Setuju } \\
\text { f (\%) }\end{array}$ & $\begin{array}{c}\text { Tidak } \\
\text { Setuju } \\
\text { f ( } \%)\end{array}$ \\
\hline 1. & $\begin{array}{l}\text { Tidak bermanfaat } \\
\text { karena bisa memerah } \\
\text { ASI di mana saja }\end{array}$ & $16(20,2)$ & $63(79,8)$ \\
\hline 2. & $\begin{array}{l}\text { Pimpinan mendukung } \\
\text { saat ingin memerah ASI } \\
\text { Tidak memberikan ASI }\end{array}$ & $79(100)$ & $0(0,0)$ \\
\hline 3. & $\begin{array}{l}\text { bila tidak tersedia } \\
\text { ruang laktasi }\end{array}$ & $12(15,8)$ & $67(84,2))$ \\
\hline 4. & $\begin{array}{l}\text { Tidak membutuhkan } \\
\text { ruang laktasi karena } \\
\text { memberikan susu } \\
\text { formula }\end{array}$ & $13(16,5)$ & $66(83,5)$ \\
\hline 5. & Adanya ruang laktasi & & \\
\hline
\end{tabular}




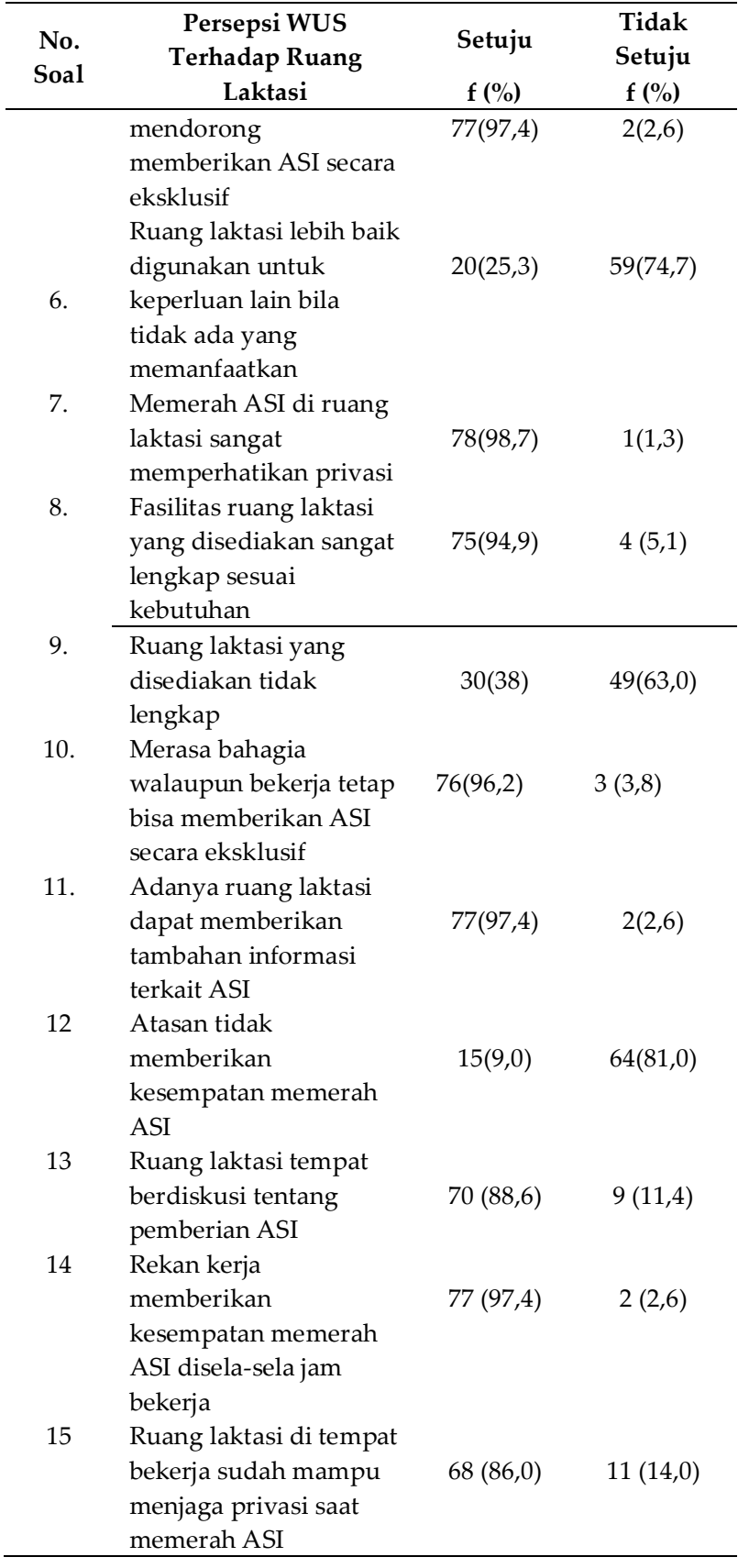

\section{Pengetahuan dan Persepsi WUS}

Tabel 6 berikut ini menunjukkan hasil tabulasi silang antara variabel pengetahuan dengan variabel persepsi.

Tabel 6. Pengetahuan dan Persepsi Wus

\begin{tabular}{lcrc}
\hline $\begin{array}{l}\text { Pengetahuan } \\
\text { Terhadap } \\
\text { Ruang Laktasi }\end{array}$ & \multicolumn{2}{c}{ Persepsi Terhadap Ruang } & Laktasi \\
\hline Baik & $44(77,2)$ & $13(22,8)$ & Total \\
Cukup & $7(31,8)$ & $15(68,2)$ & Kurang(\%) \\
\hline Total & $\mathbf{5 1 ( 6 4 , 6 )}$ & $\mathbf{2 8}(\mathbf{3 5 , 4 )}$ & $\mathbf{7 9 ( 1 0 0 , 0 )}$ \\
\hline
\end{tabular}

Berdasarkan tabel di atas dapat dilihat bahwa sebagian besar WUS dengan pengetahuan baik terhadap ruang laktasi memiliki persepsi yang baik juga terhadap ruang laktasi. Dari 57 WUS dengan tingkat pengetahuan baik terhadap ruang laktasi sebanyak $77,2 \%$ memiliki persepsi baik terhadap ruang laktasi.

\section{DISKUSI}

\section{Pengetahuan WUS Terhadap Ruang} Laktasi

Hasil dari penelitian ini menunjukan bahwa sebagian besar WUS di empat instansi pemerintah wilayah Kota Denpasar memiliki pengetahuan yang baik terhadap ruang laktasi (72,2\%). Instansi BKKBN dan Imigrasi seluruhnya memiliki pengetahuan baik $(100 \%)$. Hasil penelitian ini sejalan dengan penelitian yang dilakukan oleh Sefiana (2014) bahwa pengetahuan responden dipengaruhi dari pengalaman menyusui sebelumnya, dimana pengalaman ini akan memperbesar kemungkinan ibu untuk memberikan ASI eksklusif dengan memanfaatkan ruang laktasi. Hal ini sesuai dengan teori dari Notoatmodjo (2007) yang menyatakan bahwa dengan pendidikan yang tinggi maka orang tersebut akan semakin luas pula pengetahuannya. Penelitian yang dilakukan oleh Ika Wulandari (2015) pada ibu yang bekerja di wilayah puskesmas Bangutapan Yogyakarta sebanyak 47,73 \% ibu mempunyai pengetahuan yang kurang tentang pemanfaatan ruang laktasi. Menurut teori Notoatmodjo (2007) hal ini dilatarbelakangi pendidikan SD dan SMP disamping itu juga tidak pernah mendapatkan informasi dan tidak memiliki pengalaman sama sekali 
dalam pemberian ASI Eksklusif di ruang laktasi. Melihat dari hasil penelitian, maka perlu dilakukan usaha untuk memberikan informasi dan motivasi serta meningkatkan pengetahuan ibu bekerja tentang prinsip pemberian ASI Eksklusif baik secara langsung, maupun tidak langsung. Pemberian secara langsung yaitu dengan cara menyusui sedangkan, pemberian ASI secara tidak langsung dilakukan dengan cara memerah atau memompa lalu ASI tersebut disimpan untuk kemudian diberikan pada bayi. Hal yang perlu diupayakan untuk meningkatkan penggunaan ruang laktasi adalah membuat regulasi yang mengatur agar kantor-kantor atau pihak Perusahaan menyediakan Taman Penitipan Anak (TPA) agar ibu selalu dekat dengan bayinya dan dapat memberikan ASI sesuai dengan kebutuhan bayi atau bila memungkinkan, bisa disediakan fasilitas ruang laktasi yaitu tempat untuk memeras dan menyimpan ASI. Menyusui sebenarnya tidak saja memberi kesempatan pada bayi untuk tumbuh menjadi manusia yang sehat secara fisik saja, tetapi juga lebih cerdas, mempunyai emosional yang stabil, perkembangan spiritual yang baik, serta perkembangan sosial yang lebih baik (Roesli, 2010).

Dari komponen pengetahuan dapat diketahui bahwa sebagian besar WUS sudah dapat menjawab pertanyaan pengetahuan dengan benar, namun masih terdapat sebanyak 40,5\% WUS yang kurang mengetahui sarana dan prasana yang harus ada di ruang laktasi hal ini menunjukkan kurang disosialisasikannya ruang laktasi kepada instansi tempat WUS bekerja. Peraturan PERMENKES RI Nomor 15 Tahun
2013 (pasal 1 ayat 3), mengatakan bahwa ruang laktasi adalah ruangan yang dilengkapi dengan prasarana menyusui dan memerah ASI. Sedangkan sarana yang sekurang-kurangnya harus ada di dalam ruang laktasi adalah peralatan menyimpan ASI dan peralatan pendukung lainnya. Peralatan menyimpan ASI yaitu lemari pendingin (refrigerator) untuk menyimpan ASI, gel pendingin (ice pack), tas untuk membawa ASI perahan (cooler bag), sterilizer botol ASI.

Dari jumlah total responden 79 WUS diketahui bahwa sebagian besar responden berumur 28-35 tahun yaitu sebanyak 45 responden (57\%). Karakteristik umur WUS 28-35 tahun sangat mempengaruhi dalam pemberian ASI eksklusif pada saat bekerja. Hal ini sesuai dengan pendapat Slamet (2013), yang menyatakan bahwa umur mempunyai kaitan dengan tingkat kedewasaan psikologis yang menunjukkan kematangan dalam arti individu menjadi semakin bijaksana dalam mengambil keputusan khususnya mengenai nutrisi bagi bayi. Sebagian besar responden di empat instansi pemerintah wilayah Kota Denpasar memiliki status pekerjaan sebagai karyawan dan masih tetap memberikan ASI secara eksklusif sebanyak $74,5 \%$. Faktor lain menurut peneliti dipengaruhi oleh hal yang memungkinkan juga mempengaruhi pengetahuan WUS akan semakin baik karena WUS yang bekerja akan lebih banyak memiliki pengalaman dan mendapatkan informasi mengenai sumber nutrisi bayi dan pentingnya pemberian ASI Eksklusif sehingga WUS yang bekerja memanfaatkan fasilitas ruang laktasi yang disedikan pada kantor tempat ibu bekerja. Sesuai dengan 
teori dari Anoraga (2014) bahwa pekerjaan merupakan suatu aktivitas yang dilakukan seseorang untuk memperoleh penghasilan guna memenuhi kebutuhan setiap hari. Pekerjaan merupakan salah satu faktor yang mempengaruhi penegtahuan. Seseorang yang bekerja akan sering berinteraksi dengan orang banyak sehingga memiliki pengetahuan yang baik pula. Hal ini sesuai dengan teori dari Dewi (2011) bahwa bagi ibu yang bekerja, menyusui tidak perlu dihentikan sebab bukan menjadi alasan ibu bekerja untuk tidak memberikan ASI Eksklusif pada bayinya melainkan ibu bekerja harus tetap memberikan ASInya dengan cara diperah dan kemudian disimpan pada lemari pendingin.

\section{Persepsi WUS Terhadap Ruang Laktasi}

Hasil dari penelitian ini menunjukkan bahwa $64,6 \%$ WUS di instansi pemerintah wilayah Kota Denpasar memiliki persepsi baik terhadap ruang laktasi. Hal ini sesuai dengan teori Walgito (2010), menyebutkan persepsi dapat dipengaruhi dengan pengetahuan dan pengalaman seseorang tentang penggunaan ruang laktasi. Hasil tersebut sejalan dengan penelitian Amelia (2016) tentang persepsi WUS yang bekerja terhadap pentingnya ketersediaan ruang laktasi di lingkungan Universitas Muhammadiyah Surakarta yang dilakukan dengan wawancara mendalam tentang persepsi digali dengan mengkaji faktorfaktor internal dan eksternal didapatkan bahwa WUS yang bekerja dan akan memiliki bayi membutuhkan ruang laktasi yang digunakan untuk memerah ASI dan menyimpan ASI pada saat bekerja sehingga pemberian ASI eksklusif tetap berlangsung.
Persepsi responden terhadap ruang laktasi mendorong WUS yang sedang menyusui memberikan ASI secara eksklusif. Hal ini akan berdampak pada respon dan perilaku terhadap penggunaan ruang laktasi. Dalam hal ini sejalan dengan penelitian yang dilakukan oleh Kristiarini (2011) mengatakan bahwa apabila pengetahuan responden semakin baik, maka persepsi semakin positif. Berdasarkan teori yang ada menyatakan bahwa salah satu faktor yang mempengaruhi persepsi yaitu pengetahuan, dimana semakin banyak pengetahuan yang dimiliki, semakin baik persepsi yang dimilikinya (Notoadmodjo, 2010).

Persepsi seseorang dimulai dari penglihatan hingga terbentuk tanggapan yang terjadi dalam diri individu sehingga individu sadar akan segala sesuatu dalam lingkungannya melalui indera-indera yang dimilikinya. Faktor yang mempengaruhi persepsi ada dua yaitu faktor eksternal dan faktor internal. Salah satunya faktor eksternal yaitu informasi yang diperoleh, pengetahuan, dan hal-hal baru atau ketidakasingan suatu objek. Sedangkan faktor internal yaitu pengalaman seseorang tentang hal yang mempengaruhi individu serta motivasi akan kebutuhan sehingga berpengaruh terhadap persepsi seseorang.

Berdasarkan hasil penelitian sebanyak $97,4 \%$ WUS menyatakan bahwa adanya ruang laktasi mendorong mereka untuk memberikan ASI secara eksklusif namun masih terdapat $25,3 \%$ WUS yang menyatakan setuju bila ruang laktasi digunakan untuk keperluan lain. Hal ini menunjukkan bahwa mereka belum menyadari kegunaan ruang laktasi untuk ibu yang ingin memerah dan menyimpan 
ASI agar menjaga kenyamaanan dan privasi WUS saat melakukan kegiatan yang berkaitan dengan pemberian ASI. Ruang laktasi juga perlu dijaga kebersihannya agar proses menyusui ataupun memerah ASI tidak terkontaminasi, sehingga ruang laktasi tidak boleh digabung penggunaannya untuk keperluan lain selain untuk kegiatan pemberian ASI. Sebanyak 96,2\% WUS merasa bahagia tetap bisa memberikan ASI secara eksklusif walaupun sibuk bekerja. Rekan kerja pun memberikan kesempatan bagi WUS yang ingin memerah ASI di sela jam kerja. Sebanyak 38\% WUS menyatakan sarana dan prasarana yang terdapat di ruang laktasi belum lengkap. Karena fasilitas ruang laktasi yang tidak lengkap membuat WUS malas memerah ASI.

\section{SIMPULAN}

Dari penelitian ini dapat disimpulkan bahwa sebagian besar $(72,2 \%)$ pengetahuan WUS di Instansi Pemerintah wilayah Kota Denpasar terhadap ruang laktasi berada pada tingkat pengetahuan baik. Persepsi WUS di Instansi Pemerintah wilayah Kota Denpasar terhadap ruang laktasi sebagian besar pada kategori baik $(64,6 \%)$.

\section{SARAN}

Diharapkan kepada tenaga kesehatan agar lebih mensosialisasikan tentang pemanfaatan ruang laktasi ke seluruh instansi baik instansi pemerintah maupun swasta. Serta Kepada instansi-instansi tempat WUS bekerja agar dapat menyediakan ruang laktasi dengan fasilitas yang lengkap dan kondisi ruangan yang nyaman sehingga Ibu menyusui dapat tetap memberikan ASI secara eksklusif meskipun sedang bekerja.

\section{DAFTAR PUSTAKA}

Anoraga,P. (2014). Psikologi Kerja. Jakarta: Rineka Cipta

Asosiasi Ibu Menyusui Indonesia. (2013). Lingkungan Kerja Ramah Laktasi: Pedoman untuk Perusahaan. Jakarta

Arikunto, S. (2010). Prosedur Penelitian: Suatu Pendekatan Praktik. Jakarta: Rineka Cipta

Ayu,R. (2011). Faktor-Faktor yang berhubungan dengan Pemberian ASI Eksklusif di Kecamatan Salawu dan Sukahening Kabupaten Tasikmalaya Tahun 2010. Jurnal Penelitian. Tasikmalaya : Stikes Respati

Cadwell,K.,Turner,C. (2011). Manajemen Laktasi. Alih Bahasa: Estu Tiar. Jakarta : EGC.

Depkes. RI. (2012). Kebijakan Departemen Kesehatan tentang Peningkatan Pemberian Air Susu Ibu (ASI) Pekerja Wanita. Jakarta: Pusat Kesehatan Kerja Depkes RI.

Data Cakupan Nasional Departemen Kesehatan Republik Indonesia Tahun 2011. www.depkes.go.id

Desi,A. (2013). Tingkat Pengetahuan tentang Penyimpanan ASI pada Ibu Bekerja di Asrama Polisi Kalisari Semarang Kecamatan Semarang Selatan. Jurnal Keperawatan. FIKKES. Volume 1 No.2 Maret 2008

Dewi,R. (2012). Mengatasi Konflik Peran sebagai Karyawan dan Ibu Rumah Tangga pada Tenaga Kerja Wanita di Indonesia. Jurnal Kesehatan. Volume XXIII No 2 April-Juni 2007.

Dizon, D. (2013) Wanita Usia Subur. Jakarta: Indeks Media. 
Karyati,U. (2010). Hubungan Pengetahuan tentang Manajemen Laktasi Ibu Primipara dengan Teknik Laktasi di Ruang Post Partum RSU Kota Surakarta. Skripsi, Surakarta:UMS.

Keputusan Menteri Kesehatan Republik Indonesia $\quad$ 450/Menkes/SK/IV/2004 tentang pemberian AIR Susu Ibu (ASI) secara Eksklusif pada Bayi di Indonesia

Kristiyanasari, (2011). ASI, Menyusui $\mathcal{E}$ SADARI. Penerbit Nuha Medika, Yogyakarta.

Toha,M. (2014). Perilaku Organisasi Konsep Dasar dan Aplikasinya. Jakarta: Grafindo Persada.

Notoadmodjo, S. (2007). Pengantar Promosi Kesehatan dan Aplikasi Ilmu Prilaku. Jakarta: Rineka Cipta.

Notoatmodjo, S. (2012). Metodologi Penelitian Kesehatan. Jakarta: Rineka Cipta.

Peraturan Pemerintah Nomor 33 tahun 2012 tentang ASI Eksklusif

Peraturan Menteri Kesehatan Republik Indonesia Nomor 15 Tahun 2013 tentang Ruang Laktasi

Perinasia. (2009). Bahan Bacaan Manajemen Laktasi, Cetakan ke 2, Program Manajemen Laktasi. Jakarta :Perinasia

Pratiwi,D.M. (2016). Analisis Faktor Penghambat Pemanfaatan Ruang Menyusui di Tempat Kerja Pada Pekerja Wanita di PT. Daya Manunggal, Unnes Journal of Public Health, $5: 2$.

Proverawati, A., Eni, R. (2010). Kapita Selekta ASI dan Menyusui. Yogyakarta : Nuha Medika.

Republik Indonesia. (2008). Peraturan Bersama Menteri Negara Pemberdayaan Perempuan, Menteri Tenaga Kerja Dan Transmigrasi, Dan Menteri Kesehatan Nomor 48/Men.PP/XII/2008,
Per.27/Men/XII/2008,

Dan

1177/Menkes/PB/IIi/2008

Tentang

Peningkatan Pemberian Air Susu Ibu Selama Waktu Kerja Di Tempat Kerja, Jakarta : Sekretariat Negara.

Roesli, U. (2010). Mengenal ASI eksklusif. Jakarta : PT. Pustaka Pembangunan Swadaya Nusantara

Sefiana, (2014). Faktor yang Mempengaruhi Sikap Ibu Menyusui Terhadap Pemanfaatan Ruang Menyusui di RSIA Sakina Idaman Yogyakarta. STIKES 'Aisyiyah Yogyakarta. Walgito, (2010). Pengantar Psikologi Umum. Yogyakarta: C.V Andi Offset.

Wawan \& Dewi. (2011). Teori \& Pengukuran Pengetahuan, Sikap dan Perilaku Manusia. Yogyakarta: Nuha Medika.

Wulandari,I. (2015). Karakteristik Ibu Bekerja Yang Berhasil Memberikan ASI Eksklusif Pada Bayi Di Puskesmas Banguntapan 1 Bantul. Yogyakarta: STIKES Jenderal Achmad Yani Yogyakarta. 